\title{
Yield Stability of Sweet Sorghum Genotypes for Bioenergy Production Under Contrasting Temperate and Tropical Environments
}

\author{
Diana-Abasi Udoh ${ }^{1}$, Søren K. Rasmussen ${ }^{1}$, Sven-Erik Jacobsen ${ }^{1}$, Godfrey A. Iwo ${ }^{2} \&$ Walter de Milliano ${ }^{3}$ \\ ${ }^{1}$ Department of Plant and Environmental Sciences, Plant Breeding Research Group, University of Copenhagen, \\ DK-1871 Frederiksberg C, Denmark \\ ${ }^{2}$ Department of Crop Science, Faculty of Agriculture, University of Calabar, Calabar, Nigeria \\ ${ }^{3}$ Hoeve Dierkensteen' Bakkersstraat 62, 4501 RB Oostburg, The Netherlands \\ Correspondence: Godfrey Akpan Iwo, Department of Crop Science, Faculty of Agriculture, University of \\ Calabar, PMB 1115, Calabar, Nigeria. E-mail: akpaniwo@yahoo.com
}

Received: August 12, 2018

Accepted: September 22, 2018

Online Published: November 15, 2018

doi:10.5539/jas.v10n12p42

URL: https://doi.org/10.5539/jas.v10n12p42

\begin{abstract}
Forty-three sweet sorghum accessions were grown in two contrasting environments; Nigeria (tropical environment) and Denmark (temperate environment). The objectives were to determine the interaction between genotype and environment on grain yield, fresh biomass and stem sugar, and to assess yield stability of sweet sorghum and identify the best genotypes for biofuel production. The sweet sorghum originating from a Dutch and ICRISAT collection was grown in randomized complete block design in three replicates for two years (2014 and 2015). The combined analysis of variance of the sweet sorghum genotypes in two years over the two contrasting environments revealed that year $(\mathrm{Y})$, genotype $(\mathrm{G})$, environment $(\mathrm{E})$ and genotype by environment interaction (GEI) were significant in the entire biofuel yield attributes obtained from both Dutch and ICRISAT collections except the degree of Brix and fresh biomass respectively across the year. The year and genotype interaction $(\mathrm{Y} \times \mathrm{G})$ was not significant in all the biofuel attributes of Dutch accessions. Additive main effect and multiplicative interaction (AMMI) analysis of variance showed significant effect of G, E and the GEI. The AMMI was used to identify the best performing, adaptable and more stable genotypes. Twenty-two genotypes of both ICRISAT and Dutch accessions were identified to be stable across the two locations with respect to different biofuel attributes. Nine, seven, and six genotypes were found to be stable for grain yield, biomass yield and brix value, respectively. The best performing genotypes for stem sugar across locations were identified. From the available data collected, the performance of the sweet sorghum was attributed to both genetic and environmental effects. High GE was observed to influence stability, hence will influence the selection criteria of the sweet sorghum genotypes.
\end{abstract}

Keywords: AMMI, biomass, degrees Brix, GxE interaction, stem sugar

\section{Introduction}

Sweet sorghum (Sorghum bicolor L.) is a multipurpose crop grown for food, feed and fuel due to its high sugar level in the stem (Regassa and Wortmann, 2014). It is similar to grain sorghum but exhibits rapid growth, higher production, and wider adaptation. It has great potential for ethanol production. As a drought tolerant crop, it remains the most desirable alternative to other cereals. Sweet sorghum accumulates high amount of fermentable sugars in the stem and the ethanol from sweet sorghum is said to be cleaner than ethanol from sugarcane when mixed with gasoline (Belum et al., 2010). It compares well with sugarcane or corn when viewed from the perspective of energy balance between production and available extracted energy. Sweet sorghum produces eight units of energy for every unit of energy invested in its cultivation and production (Amosson et al., 2011). The crushed stalks or the bagasse could be used for cellulosic ethanol production and the grain may be used for ethanol production from the starch (Rajvanshi \& Nimbker, 2003). Sweet sorghum is a potential biofuel crop as it is capable of producing high yields of ethanol from a combination of easily fermentable sugar and lignocellulosic bagasse. This is essential to meet the renewable fuel standard (RFS) which calls for production of 36 billion gallons or 144 billion litres of renewable fuel by 2020 (Stevens, 2014). 
The biofuel produced from agricultural biomass provides a sustainable and eco-friendly energy option that fosters environmental sustainability as compared to other renewable sources. This led to economic consideration in production of sweet sorghum with emphasis on high grain yield, biomass as well as sugar yield. Plant breeding procedures require conduct of yield trials of crop genotypes in a number of environments. Such trials provide useful information on cultivar performance, adaptation and genotype by environment interaction, which are necessary for cultivar selection. Since yield and yield attributes are controlled by complex polygenes, their expression strongly depends on environmental conditions. Multi-environment trials (MET) are conducted to evaluate yield stability and performance of genetic materials under varying environmental conditions (Yan \& Rajcan, 2002). A genotype grown in different environments will frequently show significant variation in yield performance. These changes are influenced by the genotype by environment interaction (GEI). Genotypes by environment interaction (GEI) sometimes complicate selection of superior genotypes (Ramagosa et al., 2013) making ranking of genotypes or correlation between genotype and phenotype difficult. Yield stability analysis therefore is an important step in developing cultivars for a wide range of environments or for specific location. AMMI analysis is used to determine stability of genotypes across locations using the principal component axis (PCA) scores and AMMI stability value (ASV). The purpose of the study therefore was to determine:

(a) Interaction between genotypes and environments for grain yield, fresh biomass and degrees Brix.

(b) The yield stability of sweet sorghum genotypes across the contrasting environments (tropical and temperate environment)

(c) To identify the best sweet sorghum genotypes for biofuel production under tropical and temperate environments.

\section{Materials and Methods}

\subsection{Plant Material and Field Trials}

The experimental material consisted of 26 sweet sorghum accessions obtained from ICRISAT (International Crops Research Institute for the Semi-Arid Tropics), India and 17 Dutch accessions obtained from the Netherlands which were grown during 2014 and 2015 cropping seasons. The field trial was conducted at Taastrup Campus $\left(55^{\circ} 40^{\prime} \mathrm{N}\right.$ and $12^{\circ} 18^{\prime} \mathrm{E}$ ) of University of Copenhagen, Denmark (DNK) and National Cereals Research Institute, Badeggi $\left(09^{\circ} .04^{\prime} \mathrm{N}\right.$ and $\left.06^{\circ} .08^{\prime} \mathrm{E}\right)$ in Nigeria (NGA). The Badeggi location had an average annual rainfall of 1,104 $\mathrm{mm}$ with Ferrosol type of soil while Taastrup had average rainfall of $313.9 \mathrm{~mm}$ between June and December in both cropping seasons. The experiment was laid out in randomized complete block design with three replications. A single row plot of $10 \mathrm{~m} \times 0.75 \mathrm{~m}$ was maintained with inter-row and intra-row spacing of $75 \mathrm{~cm}$ and $30 \mathrm{~cm}$, respectively. Two plants per stand were maintained after thinning with maximum of 33 plants per plot. In Nigeria, application of mixed inorganic fertilizer (NPK 15:15:15) was applied at the rate of 80 $\mathrm{kg} / \mathrm{ha}$ to ensure top dressing at sowing and with urea fertilizer incorporated as side dressing. In Denmark, the fertilizer composition was $27 \%$ nitrogen and $4 \%$ sulphur. It was applied at four weeks after germination and at the initiation of shoot arrowing. Other cultural practices included weeding at four weeks interval until harvesting commenced.

Data on plant height was collected by measuring 8 plants per plot using meter ruler to measure from the base to the top of the shoot leaves. The degrees Brix $\left({ }^{\circ} \mathrm{Bx}\right)$ was determined from 8 plants randomly cut per plot and the sugar concentration (Brix value) was measured at the third and seventh internode (from the top) using refractometer. Fresh biomass weight on the other hand was determined from all the plants per plot. Plants were harvested (stalk + leaves) without panicle and weighed using a weighing balance. Grain yield (GY) was determined after the harvested panicles with grains were dried and the seeds were threshed from panicle and weighed per plot using a weighing balance. A combined analysis of variance (ANOVA) was carried out using Genstat 8.1 version and the significant GEI was further substantiated by using different statistical tools. The means of all parameters were recorded. The Duncan Multiple Range Test was used for the comparison of means at $1 \%$ and $5 \%$ probability level. AMMI Model analysis was used to analyse genotype by environment interaction. The two locations and the two years form a combination of four environments. The environments are E1 (Denmark, 2014), E2 (Denmark, 2015), E3 (Nigeria, 2014) and E4 (Nigeria, 2015).

AMMI Model:

$$
\text { Yij }-\mu-\beta_{\mathrm{i}}-\alpha_{\mathrm{i}}=\mathrm{jij}
$$

where,

Yij $=$ the measure mean of the $\mathrm{i}^{\text {th }}$ genotype in $\mathrm{j}^{\text {th }}$ environment; $\mu=$ the grand mean; $\alpha_{\mathrm{i}}=$ the main effect of $\mathrm{j}^{\text {th }}$ genotype; $\beta=$ the main effect of the $j^{\text {th }}$ environment; $j=$ the interaction between $i^{\text {th }}$ genotype and $j^{\text {th }}$ environment. 
The nature of genotype by environment interaction was investigated with the use of AMMI model (IRRI, 2007) which combines the standard analysis of variance with principal component analysis (Zobel et al., 1988).

Genotype stability ranking in these studies was calculated using the formula by Purchase (1997) as follows:

$$
\mathrm{ASV}=\sqrt{\frac{\text { SSIPCA1 }_{\text {SSIPCA2 }}(\text { IPCA } 1 \text { Score })^{2}+(\text { IPCA } 2 \text { Score })^{2}}{2}}
$$

where,

$\mathrm{ASV}=\mathrm{AMMI}$ stability value; SSIPCA = Interactive Principal Component Analysis sum of Squares 1 and 2; IPCA 1 and 2 Score $=$ Interactive Principal Component Analysis 1 and 2 scores.

\section{Results}

The performance of each genotype considering the biofuel related traits such as plant height, fresh weight biomass, brix level and grain yield across two locations for two years is presented in Tables $1 \mathrm{a}$ and $\mathrm{b}$. The mean comparison of the sweet sorghum genotypes across the two locations revealed significant differences in performance among the genotypes. The significant differences at $p<0.01$ in each of the traits among the genotypes indicated variations in genetic constitution of the accessions. The plant height differed among the tested sweet sorghum genotypes across locations. Among the Dutch accessions the plant height ranges from 124 $\mathrm{cm}-167 \mathrm{~cm}$ in Denmark and $41 \mathrm{~cm}$ to $161 \mathrm{~cm}$ in Nigeria. The plant height of the ICRISAT accessions ranges from $127 \mathrm{~cm}$ to $196 \mathrm{~cm}$ in Denmark and $124 \mathrm{~cm}$ to $237 \mathrm{~cm}$ in Nigeria. The genotypic effect and the contrasting effect of temperate and tropical climatic conditions influenced the plant height. In Denmark, the highest plant height was recorded on HI/Sn-PDI-R47 $(167 \mathrm{~cm})$ and F5.335 m10-1/6-6 $(196 \mathrm{~cm})$ of both Dutch and ICRISAT accession, respectively. The highest plant heights from Nigeria environment were obtained from H3-R9-32/3n $(182.5 \mathrm{~cm})$ and F5-3.SSN 10-2012-1 $(236.8 \mathrm{~cm})$ of both Dutch and ICRISAT accessions respectively. This indicated that the environments influence the height of the sorghum genotype.

The grain yield of the genotypes also varied with environments. Among the genotypes, H1-PDI-R47, F5.3 SSM10-13/7-1, F7.5 SSM09-1-1/7-1 gave the highest grain yield in Denmark while H3-R9-32/sn and F5.3SSM10-12/2-3 gave the highest grain yield in Nigeria. The grain yield varied according to differences in genotypes and environments which indicated that there is no specific location favours grain yield performance of the sweet sorghum genotypes.

The fresh biomass weight also differed significantly among the sweet sorghum genotypes across the two locations. The biomass weight tends to be higher among all the genotypes except H8-PD3-R51 which had the least performance across the locations. Fresh biomass weight is an important yield attribute to both juice yield, sugar content and ethanol production. According to Panhwar et al. (2003) it has a positive correlation with yield and other related traits.

The degrees Brix also differed significantly among the sweet sorghum genotypes across the two contrasting environments. High Brix values were recorded among the genotypes cultivated in Denmark than in Nigeria. This is an indication of genotype discrimination among the environment. Most of the high Brix values were recorded for the ICRISAT accessions (Table 1a and b). The results indicate that the genotypes with high fresh biomass weight are associated with high Brix values. Six genotypes: F5.3SSM10-15/5-1, F5.3SSM10-18/2-1, F5.3SSM10-20/2-1, F5.3SSM10-2/6-1, F7.5SSM09-1-1/7-1 and F7.5SSM09-1-1/9-2 recorded high fresh biomass weight with corresponding high degrees Brix. 
Table 1a. Mean values for biofuel yield related components of ICRISAT sweet sorghum accessions across two contrasting environments

\begin{tabular}{|c|c|c|c|c|c|c|c|c|}
\hline \multirow{2}{*}{ Genotype } & \multicolumn{2}{|c|}{ Plant Height $(\mathrm{cm})$} & \multicolumn{2}{|c|}{ Grain Yield (g/plot) } & \multicolumn{2}{|c|}{ Fresh Biomass (g/plot) } & \multicolumn{2}{|c|}{ Brix Value \% } \\
\hline & Denmark & Nigeria & Denmark & Nigeria & Denmark & Nigeria & Denmark & Nigeria \\
\hline F5.3 SSM10-1/1-8 & $167.2 \mathrm{~b}$ & $189.3 \mathrm{~b}$ & $210 \mathrm{~d}$ & $690 \mathrm{~b}$ & $1020 \mathrm{bc}$ & $1650 \mathrm{bc}$ & $11.70 \mathrm{~cd}$ & $8.67 b c$ \\
\hline F5.3 SSM10-1/5-1 & $167.7 \mathrm{~b}$ & $161.5 \mathrm{bc}$ & $80 f$ & $453 c$ & $625 \mathrm{ce}$ & $1350 \mathrm{c}$ & $11.40 \mathrm{~d}$ & $8.65 \mathrm{bc}$ \\
\hline F5.3 SSM10-1/6-1 & $163.5 b$ & $186.3 b$ & $215 b$ & $325 \mathrm{~cd}$ & $1008 \mathrm{c}$ & $1055 \mathrm{c}$ & $11.20 \mathrm{~d}$ & $8.90 \mathrm{bc}$ \\
\hline F5.3 SSM10-1/6-6 & $196.0 \mathrm{a}$ & $124.3 \mathrm{~cd}$ & $483 b$ & $950 \mathrm{ab}$ & $2000 \mathrm{ab}$ & $2150 \mathrm{~b}$ & $11.55 \mathrm{~cd}$ & $8.40 \mathrm{bc}$ \\
\hline F5.3 SSM10-12/2-3 & $129.2 \mathrm{c}$ & $168.8 \mathrm{bc}$ & $120 \mathrm{ef}$ & $1110 \mathrm{a}$ & $695 \mathrm{~cd}$ & $3000 a$ & $12.65 \mathrm{~cd}$ & $8.75 b c$ \\
\hline F5.3 SSM10-13/7-1 & $157.2 \mathrm{bc}$ & $141.7 \mathrm{c}$ & $585 a$ & $455 \mathrm{c}$ & $1945 \mathrm{ab}$ & $1275 \mathrm{c}$ & $12.90 \mathrm{~cd}$ & $6.75 c$ \\
\hline F5.3 SSM10-14/1-1 & $146.8 \mathrm{c}$ & $223.2 \mathrm{ab}$ & $155 \mathrm{e}$ & $425 \mathrm{c}$ & $650 \mathrm{~cd}$ & $1230 \mathrm{c}$ & $11.35 \mathrm{~d}$ & $7.95 \mathrm{c}$ \\
\hline F5.3 SSM10-15/5-1 & $158.5 \mathrm{bc}$ & $176.3 \mathrm{~b}$ & $270 d$ & $475 c$ & $1019 \mathrm{c}$ & $1425 b c$ & $16.90 \mathrm{a}$ & $8.20 \mathrm{bc}$ \\
\hline F5.3 SSM10-16/1-1 & $153.7 \mathrm{bc}$ & $145.8 \mathrm{c}$ & $135 \mathrm{ef}$ & $745 \mathrm{ab}$ & $690 \mathrm{~cd}$ & $1800 \mathrm{~b}$ & $12.00 \mathrm{~cd}$ & $7.15 \mathrm{c}$ \\
\hline F5.3 SSM10-18/2-1 & $162.3 b$ & $116.0 \mathrm{~d}$ & $90 f$ & $75 f$ & $520 \mathrm{e}$ & $540 \mathrm{e}$ & $15.75 \mathrm{ab}$ & $11.35 b$ \\
\hline F5.3 SSM10-20/2-1 & $138.2 \mathrm{c}$ & $236.8 \mathrm{a}$ & $210 \mathrm{~d}$ & $775 \mathrm{ab}$ & $1000 \mathrm{c}$ & $1700 \mathrm{bc}$ & $15.00 \mathrm{ab}$ & $9.75 b$ \\
\hline F5.3 SSM10-21/10-1 & $159.3 \mathrm{bc}$ & $178.7 \mathrm{~b}$ & $188 \mathrm{~cd}$ & $565 c$ & $1060 \mathrm{bc}$ & $1600 \mathrm{bc}$ & $10.60 \mathrm{~cd}$ & $6.80 \mathrm{~cd}$ \\
\hline F5.3 SSM10-21/4-1 tan & $147.7 \mathrm{c}$ & $212.0 \mathrm{ab}$ & $228 \mathrm{~d}$ & $103 \mathrm{ef}$ & $1110 \mathrm{bc}$ & $495 \mathrm{e}$ & $13.25 \mathrm{c}$ & $6.45 \mathrm{~d}$ \\
\hline F5.3 SSM10-21/6-1 & $177.7 \mathrm{ab}$ & $184.3 b$ & $300 \mathrm{c}$ & $245 d$ & $1800 \mathrm{~b}$ & $935 \mathrm{~cd}$ & $14.65 \mathrm{ab}$ & $14.65 \mathrm{a}$ \\
\hline F5.3 SSM10-24/2-1 & $165.3 b$ & $208.3 \mathrm{ab}$ & $215 d$ & $565 \mathrm{e}$ & $920 \mathrm{~cd}$ & $1355 \mathrm{c}$ & $11.20 \mathrm{~cd}$ & $8.90 \mathrm{~d}$ \\
\hline F5.3 SSM10-31/2-3 & $153.0 \mathrm{bc}$ & $148.2 \mathrm{c}$ & $250 \mathrm{~d}$ & $80 f$ & $970 \mathrm{~cd}$ & $590 \mathrm{~d}$ & $10.80 \mathrm{~d}$ & $6.40 \mathrm{~b}$ \\
\hline F5.3 SSM10-31/6-3 & $161.0 \mathrm{~b}$ & $161.2 \mathrm{bc}$ & $260 \mathrm{~d}$ & $184 \mathrm{de}$ & $1090 b c$ & $835 \mathrm{~cd}$ & $9.75 \mathrm{e}$ & $10.05 b$ \\
\hline F5.3 SSM10-8/1-5 & $148.8 \mathrm{c}$ & $146.3 \mathrm{c}$ & $140 \mathrm{ef}$ & $435 c$ & $470 \mathrm{e}$ & $1250 \mathrm{c}$ & $11.55 \mathrm{~cd}$ & $9.75 b$ \\
\hline F5.3 SSM10-8/3-2 & $165.8 b$ & $174.3 b$ & $220 \mathrm{~d}$ & $423 c$ & $820 \mathrm{~cd}$ & $1275 \mathrm{c}$ & $11.50 \mathrm{~cd}$ & $7.05 \mathrm{c}$ \\
\hline F5.3 SSM10-9/1-3 & $126.8 \mathrm{~cd}$ & $207.5 \mathrm{ab}$ & $230 \mathrm{~d}$ & $505 \mathrm{bc}$ & $850 \mathrm{~cd}$ & $1445 b c$ & $14.30 \mathrm{ab}$ & $8.70 b c$ \\
\hline F7.5 SSM09-1-1/2-1 & $128.5 \mathrm{~cd}$ & $178.3 b$ & $220 \mathrm{~d}$ & $195 \mathrm{e}$ & $910 \mathrm{~cd}$ & $735 \mathrm{~cd}$ & $15.35 \mathrm{ab}$ & $10.55 b$ \\
\hline F7.5 SSM09-1-1/4-1 & $159.8 \mathrm{bc}$ & $243.3 \mathrm{a}$ & $110 \mathrm{ef}$ & $164 \mathrm{e}$ & $550 \mathrm{e}$ & $645 d$ & $8.50 \mathrm{e}$ & $8.75 b c$ \\
\hline F7.5 SSM09-1-1/6-1 & $134.5 \mathrm{c}$ & $152.7 \mathrm{bc}$ & $145 \mathrm{~cd}$ & $480 \mathrm{c}$ & $789 d$ & $1325 \mathrm{c}$ & $8.30 \mathrm{e}$ & $11.10 \mathrm{~b}$ \\
\hline F7.5 SSM09-1-1/7-1 & $165.2 b$ & $245.7 \mathrm{a}$ & $530 \mathrm{a}$ & $181 \mathrm{e}$ & $2500 \mathrm{a}$ & $895 \mathrm{~cd}$ & $15.05 \mathrm{ab}$ & $9.95 b$ \\
\hline F7.5 SSM09-1-1/9-2 & $154.2 \mathrm{bc}$ & $152.0 \mathrm{bc}$ & $300 \mathrm{c}$ & $250 \mathrm{~d}$ & $1300 \mathrm{bc}$ & $875 \mathrm{~cd}$ & $14.00 \mathrm{ab}$ & $7.35 \mathrm{c}$ \\
\hline Mult-11 36461-2-1 & $147.0 \mathrm{c}$ & $193.8 \mathrm{ab}$ & $190 \mathrm{~cd}$ & $100 \mathrm{ef}$ & $1212 b c$ & $500 \mathrm{e}$ & $9.90 \mathrm{e}$ & $7.05 \mathrm{c}$ \\
\hline
\end{tabular}

Note. Mean values in the same column carrying the same letters are not significantly different at $(\mathrm{p}<0.05 \%)$.

Table 1b. Mean values for biofuel yield related components of Dutch sweet sorghum accessions across two contrasting environments

\begin{tabular}{|c|c|c|c|c|c|c|c|c|}
\hline \multirow{2}{*}{ Genotype } & \multicolumn{2}{|c|}{ Plant Height $(\mathrm{cm})$} & \multicolumn{2}{|c|}{ Grain Yield (g/plot) } & \multicolumn{2}{|c|}{ Fresh Biomass (g/plot) } & \multicolumn{2}{|c|}{ Brix Value $\%$} \\
\hline & Denmark & Nigeria & Denmark & Nigeria & Denmark & Nigeria & Denmark & Nigeria \\
\hline H1-PD1-R47 & $146.0 \mathrm{bc}$ & $161.3 \mathrm{ab}$ & $300 \mathrm{a}$ & $1677 \mathrm{ab}$ & $1388 \mathrm{ab}$ & $3650 \mathrm{~b}$ & $7.40 \mathrm{~b}$ & $9.28 \mathrm{a}$ \\
\hline H1/sn-PD1-R47 & $167.0 \mathrm{a}$ & $109.8 \mathrm{~cd}$ & $195 \mathrm{c}$ & $154 \mathrm{e}$ & $695 \mathrm{~cd}$ & $1910 \mathrm{bc}$ & $9.30 \mathrm{a}$ & $8.35 b$ \\
\hline H18-1-PD1-R47 & $151.3 \mathrm{ab}$ & $114.3 \mathrm{~cd}$ & $187 \mathrm{c}$ & $254 d$ & $1050 \mathrm{bc}$ & $2225 b c$ & $7.00 \mathrm{~b}$ & $8.89 \mathrm{ab}$ \\
\hline H18-PD3-R51 & $132.3 \mathrm{c}$ & $115.2 \mathrm{~cd}$ & $112 \mathrm{~d}$ & $393 \mathrm{~cd}$ & $492 d$ & $2400 \mathrm{bc}$ & $8.05 b$ & $7.49 b$ \\
\hline H2-14-B1-W1 & $124.7 \mathrm{~cd}$ & $123.3 \mathrm{bc}$ & $152 \mathrm{~cd}$ & $543 \mathrm{~cd}$ & $762 \mathrm{c}$ & $2500 \mathrm{bc}$ & $9.35 \mathrm{a}$ & $9.06 \mathrm{a}$ \\
\hline H3-1-PDF-R47 & $144.2 \mathrm{bc}$ & $146.2 b$ & $189 \mathrm{c}$ & $406 \mathrm{~cd}$ & $775 \mathrm{c}$ & $1855 \mathrm{c}$ & $7.80 \mathrm{~b}$ & $6.42 \mathrm{c}$ \\
\hline H3-2-PDI-R47 & $149.5 \mathrm{bc}$ & $110.7 \mathrm{~cd}$ & $180 \mathrm{c}$ & $264 d$ & $505 d$ & $930 \mathrm{~d}$ & $5.85 \mathrm{~d}$ & $8.44 \mathrm{ab}$ \\
\hline H3-R9-32/sn & $134.2 \mathrm{c}$ & $182.5 \mathrm{a}$ & $188 \mathrm{c}$ & $2072 a$ & $723 c$ & $4650 \mathrm{a}$ & $8.75 b$ & $7.71 \mathrm{~b}$ \\
\hline H3-R9-33/sn & $134.3 \mathrm{c}$ & $143.8 \mathrm{~b}$ & $130 \mathrm{~d}$ & $420 \mathrm{~cd}$ & $655 \mathrm{~cd}$ & $3700 \mathrm{ab}$ & $7.30 \mathrm{c}$ & $7.60 \mathrm{~b}$ \\
\hline H4-1-PD1-R47 & $148.5 \mathrm{bc}$ & $122.2 b c$ & $137 d$ & $388 \mathrm{~cd}$ & $547 d$ & $2315 b c$ & $9.65 \mathrm{a}$ & $6.42 \mathrm{c}$ \\
\hline H5-1-PDI-R47 & $134.3 \mathrm{c}$ & $119.2 \mathrm{c}$ & $125 d$ & $45 \mathrm{ef}$ & $892 \mathrm{c}$ & $965 d$ & $6.90 \mathrm{c}$ & $6.36 \mathrm{c}$ \\
\hline H5-2-PD1-R47 & $126.8 \mathrm{~cd}$ & $154.5 \mathrm{ab}$ & $140 \mathrm{~d}$ & $1500 \mathrm{~b}$ & $662 \mathrm{~cd}$ & $4500 \mathrm{a}$ & $9.25 \mathrm{a}$ & $8.24 \mathrm{c}$ \\
\hline H5-B1-R8-32-R2 & $150.5 \mathrm{ab}$ & $144.2 \mathrm{~b}$ & $230 \mathrm{bc}$ & $769 c$ & $1245 b$ & $3200 \mathrm{~b}$ & $7.60 \mathrm{~b}$ & $8.98 \mathrm{ab}$ \\
\hline H8-1-PD1-R47 & $116.0 \mathrm{~d}$ & $99.8 \mathrm{~d}$ & $100 \mathrm{~d}$ & $45 \mathrm{ef}$ & $502 d$ & $1360 \mathrm{~cd}$ & $10.25 \mathrm{a}$ & $7.56 \mathrm{~b}$ \\
\hline H8-2-PD1-R47 & $124.3 \mathrm{~cd}$ & $103.7 \mathrm{~cd}$ & $152 \mathrm{~cd}$ & $210 d$ & $675 \mathrm{~cd}$ & $1850 \mathrm{c}$ & $7.40 \mathrm{~b}$ & $7.32 b$ \\
\hline H8-R9-29/sn & $154.7 \mathrm{ab}$ & $146.2 b$ & $137 \mathrm{~cd}$ & $545 \mathrm{~cd}$ & $435 \mathrm{e}$ & $1455 \mathrm{~cd}$ & $6.45 \mathrm{c}$ & $6.49 \mathrm{c}$ \\
\hline R12-23-IR & $149.3 b c$ & $120.0 \mathrm{bc}$ & $125 \mathrm{~cd}$ & $165 \mathrm{e}$ & $537 d$ & $1730 \mathrm{c}$ & $7.70 b$ & $8.07 \mathrm{ab}$ \\
\hline
\end{tabular}

Note. Means with the same letter $(\mathrm{s})$ in the same column are not significantly different $(\mathrm{p}<0.05)$ following separation by Duncan multiple Range Test. 
Combined analyses of variance of 43 sweet sorghum genotypes evaluated together in two years over the two contrasting locations (Denmark and Nigeria) are presented in Tables 2a and $2 \mathrm{~b}$. The analysis revealed that year $(\mathrm{Y})$, environment $(\mathrm{E})$, genotype $(\mathrm{G})$, genotype and environment interaction (GEI) were significant at $\mathrm{p}<0.01$ and $\mathrm{p}<0.05$ in most of the biofuel yield attributes. The year and genotype interaction $(\mathrm{Y} \times \mathrm{G})$ was not significant in biofuel attributes of Dutch accessions (Table 2b) but significant in grain weight and fresh biomass among the ICRISAT accessions (Table 2a). The genotype and GEI were significant in all the attributes except the brix level in ICRISAT accessions but significantly different in environmental effect. The implication was that there was genotype discrimination of the locations, which are similar to that in maize reported by Nzuve et al. (2013).

The significant interaction of genotypes with location (GEI) for plant height, fresh biomass weight, and grain yield except brix among ICRISAT accessions showed a differential behaviour of genotypes in the two locations. The observed variation was purely environmental. Non-significant effect of the genotype by environment interaction (GEI) in Brix level among the ICRISAT accessions indicated that genotypes did not respond differently to the Denmark and Nigeria climatic conditions. That is the performances of the sweet sorghum varieties were not location specific. The higher sum of square for environment among the ICRISAT and Dutch accessions showed that environment were diverse, influencing the biofuel attributes except the brix value. Least sum of squares on brix level expressed non- environmental effect on this trait.

Table 2a. Mean square values of combine analysis of variance for sweet sorghum obtained from India (ICRISAT accessions)

\begin{tabular}{llllll}
\hline Sources of Variation & Degree of Freedom & Plant Height $(\mathrm{cm})$ & Grain Weight $(\mathrm{kg})$ & Fresh Biomass & Brix Level (\%) \\
\hline Year & 1 & $6702^{* *}$ & $158.0^{*}$ & $259158^{* *}$ & 12.90 \\
Environment & 3 & $5204^{* *}$ & $618603.0^{* *}$ & 1337419 & $215.39^{* * *}$ \\
Genotype & 25 & $903^{*}$ & $130240^{* *}$ & $827204^{* *}$ & 9.82 \\
$\mathrm{Y} \times \mathrm{G}$ & 25 & 976 & $113109^{* *}$ & $762317^{* *}$ & 10.40 \\
$\mathrm{E} \times \mathrm{G}$ & 75 & $830^{*}$ & $53193^{* *}$ & $356110^{* *}$ & 3.79 \\
Error & 78 & 1290 & 172102 & 916499 & 14.95 \\
\hline
\end{tabular}

Note. ${ }^{* *}$ and $*$ signify significance at $\mathrm{p}<0.001$ and 0.005 respectively, $\mathrm{df}=$ degree of freedom and $\mathrm{MS}=$ mean square.

Table $2 \mathrm{~b}$. Mean square values of combined analysis of variance for sweet sorghum obtained from Netherland (Dutch accessions)

\begin{tabular}{llllll}
\hline Sources of Variation & Degree of Freedom & Plant Height $(\mathrm{cm})$ & Grain Weight $(\mathrm{kg})$ & Fresh Biomass & Brix Level (\%) \\
\hline Year & 1 & $12715.1^{* * *}$ & 146721 & 2389 & $21.077^{* *}$ \\
Environment & 3 & $6883.8^{* * *}$ & $1316024^{* *}$ & $18760398^{* * *}$ & $12.669^{* *}$ \\
Genotype & 34 & $1649.8^{* *}$ & $488855^{* *}$ & $2310259^{* *}$ & $7.703^{* *}$ \\
$\mathrm{Y} \times \mathrm{G}$ & 34 & 1186.4 & 52497 & 866316 & 3.420 \\
$\mathrm{E} \times \mathrm{G}$ & 102 & $604.7^{* *}$ & $154676^{* *}$ & $1048125^{* *}$ & $1186.4^{* *}$ \\
Error & 135 & 802.7 & 221322 & 1549014 & 604.7 \\
\hline
\end{tabular}

Note. ${ }^{* *}$ and $*$ signify significance at $\mathrm{p}<0.001$ and 0.005 respectively, $\mathrm{df}=$ degree of freedom and $\mathrm{MS}=$ mean square.

\subsection{Stability Analysis}

The additive main effect and multiplicative interaction (AMMI) models was used to evaluate the GE interactions and stability parameters of the sweet sorghum genotypes across the two locations in two years. The two locations and the two years formed a combination of four environments.

The AMMI analysis of variance for biofuel yields components tested at two contrasting environments for 2 years and the stability values are presented in Tables 3 and 4 .

The observed variations in plant height, grain yield (panicle weight), fresh biomass and Brix value showed that the performance of the sweet sorghum genotypes were influenced by environment $(E)$, genotype $(G)$ and genotypes by environment interaction (GEI). Considering both ICRISAT and Dutch accessions, the AMMI analysis for plant height showed significant differences for treatment, genotype, environment as well as 
interaction (GEI). The genotype, environment and their interaction (GEI) accounted for 9.38, 25.20, and 20.81\% of the treatment sum of squares respectively for ICRISAT and 17.75, 22.43, 32.28\% respectively for Dutch accessions. The interaction sum of squares (interaction SS) was partitioned into IPCA1, IPCA2 and residuals. The IPCA1 and IPCA2 jointly accounted for $17.07 \%$ and $31.18 \%$ of the total variation due to interaction, with IPCA1 being significant in both accessions. The environment contributed largely to variation in plant height (Table 3 and 4).This also indicated that the performance of the plant height was location specific.

The analysis for grain weight showed that the genotype, environment, and GEI were also significant and each of the variation accounted for $14.54,3.00$, and $32.18 \%$ respectively for ICRISAT accessions and 24.85, 13, 01, and $26.26 \%$ treatment sum of squares for Dutch accessions. The environmental effect was the least in the observed variation in both accessions while the interaction was the highest. The high percentage of the interaction indicated high level of instability for both environment and genotypes. The variation due to interaction was also partitioned into IPCA1 andIPCA2 which were highly significant and jointly accounted for 24.32 and $25.07 \%$ of the variations due to interaction.

The fresh biomass weight for each genotype across locations was location specific and the variation was more of genotypic effect than the location for ICRISAT accessions. The AMMI analysis showed that G, E, and GEI effect accounted for $12.84,7.32$, and $26.88 \%$ for ICRISAT and $15.63,23.80$ and $27.14 \%$ treatment sum of squares for the Dutch accessions. The environmental effect was minimal on biomass weight considering ICRISAT accessions whereas it was enormous with the Dutch accessions. The variation due to G and GEI accounted for higher percentage and this indicated high level of instability between genotype and the environment. The IPCA1 and IPCA2 were both significant and accounted for 23.88 and $26.18 \%$ of the variation.

The AMMI analysis of variance for Brix value showed that G, E and GEI were significant and accounted for 9.72, 9.61 and $37.32 \%$ for ICRISAT and $24.10,11.53$, and $31.61 \%$ for Dutch accessions as the Brix value total sum of squares. The variations were more of the genotypic effect and the interaction. The effect of GEI was higher showing that the brix level from each genotype responded differently in different environment. This also shows instability among the genotypes in sugar content. From the analysis the IPCA1 and IPCA2 jointly captured $33.34 \%$ and $30.26 \%$ of sum of squares interaction respectively of the two accessions (Table 3, 4).

\subsection{AMMI Biplot Analysis of the Biofuel Yield Attributes}

AMMI-1 biplot provides a visual expression of the relationship between the interaction principal component axis (IPCA) and the mean performance of genotypes and environment. The Figure 1, shows the relative mean performance of the genotypes and environments for brix level among the accessions. Considering ICRISAT accessions, the biplot indicated G10 (F5.3SSM10-18/2-1), G11 (F5.3SSM10-20/2-1) and G25 (F7.5SSM09-1-1/9-2) as the best performing genotypes for brix production while G16 (F5.3SSM10-31/2-3) was the least performer in brix level. The environment E1 (Denmark 2014) and E2 (Denmark 2015) were indicated as the best environment for brix production (Figure 1a). The biplot also indicated G5 (H2-14-B1-W1) as the best performing genotype among the Dutch accessions.

The Figure 2 displays IPCA1 vs mean AMMI biplot showing the relative mean performance of the genotypes and environments for fresh biomass. The biplot indicated G1 (F5.3SSM10-1/1-8), G4 (F5.3SSM10-1/6-6) and G6 (F5.3SSM10-13/7-1) as the best performing genotypes for fresh biomass weight among the ICRISAT accessions (Figure 2a). The environment E3 (Nigeria 2014) and E4 (Nigeria 2015) were indicated as the best environment for this trait than the E1 (Denmark 2014) and E2 (Denmark 2015). On the other hand, G8 (H3-R9-32/sn), G5 (H2-14-1B1-w1), G1 (H1-PD1-R47) and G12 (H5-2-PD1-R47) of Dutch accessions were the best performer in environment E2 (Denmark2015) and E3 (Nigeria 2014). These environments are indicated as mega environment. The worst performers among the accessions are G10 (H4-1-PD1-R47) and G11 (H5-1-PD1-R47) (Figure 2b).

The Figure 3 also shows the best performing genotypes and ideal environment for panicle weight which appeared to be the same as that of the fresh biomass. The best performing genotypes among the Dutch accessions for high panicle weight are G1, (H1-PD1-R47), G8 (H3-R9-32/sn) and G12 (H5-2-PD1-R47). The ideal environments for the panicle weight are E2 (Denmark, 2015) and E3 (Nigeria 2014) (Figure 3b). 
Table 3. Additive main effect and multiplicative interaction analysis of variance for plant height $(\mathrm{cm})$, panicle weight $(\mathrm{kg})$, fresh biomass and percentage brix ICRISAT accessions

\begin{tabular}{|c|c|c|c|c|c|c|c|c|c|c|c|c|c|}
\hline \multirow{2}{*}{ Source } & \multirow{2}{*}{$\mathrm{DF}$} & \multicolumn{3}{|c|}{ Plant height $(\mathrm{cm})$} & \multicolumn{3}{|c|}{ Grain weight (kg) } & \multicolumn{3}{|c|}{ Biomass } & \multicolumn{3}{|c|}{ Brix level (\%) } \\
\hline & & SS & MS & Explained \% & SS & MS & Explained \% & SS & MS & Explained \% & SS & MS & Explained \% \\
\hline Total & 207 & 2615.1 & 12.63 & & 142204568 & 686979 & & 25353194 & 122479 & & 232196 & 1122 & \\
\hline Treatment & 103 & 1448.7 & $14.07 *$ & 55.39 & 70717678 & $686579^{* *}$ & 49.72 & 1192916 & $115817^{* * *}$ & 47.1 & 131550 & $1277^{* *}$ & 56.64 \\
\hline Genotype & 25 & 245.5 & $9.82 *$ & 9.38 & 20680107 & $827204 * *$ & 14.54 & 3256011 & $130240^{* *}$ & 12.84 & 22573 & $903^{*}$ & 9.72 \\
\hline Environment & 3 & 659.1 & $219.69 * *$ & 25.2 & 4271417 & $1423086^{*}$ & 3 & 1855967 & $618656^{*}$ & 7.32 & 22313 & $7438 * *$ & 9.61 \\
\hline Blocks & 4 & 233.2 & 58.3 & 8.92 & 12095823 & 3023956 & 8.5 & 20078950 & 519738 & 8.199 & 4565 & 1141 & 1.97 \\
\hline Interaction & 75 & 544.2 & $7.26^{*}$ & 20.81 & 45766154 & $610215^{* *}$ & 32.18 & 6817183 & $90896^{* *}$ & 26.88 & 86665 & $1156^{*}$ & 37.32 \\
\hline IPCA 1 & 27 & 310.3 & $11.49^{*}$ & 11.86 & 19423363 & $719384 * *$ & 13.66 & 4155983 & $153925^{* *}$ & 16.39 & 56096 & $2078^{*}$ & 24.16 \\
\hline IPCA 2 & 25 & 130.3 & 5.21 & 4.98 & 15017144 & $600686^{*}$ & 10.56 & 1897976 & 75919 & 7.49 & 21335 & 853 & 9.18 \\
\hline Residual & 23 & 103.6 & 4.5 & 3.96 & 11325647 & 482419 & 7.96 & 763225 & 33184 & 3 & 9234 & 401 & 3.97 \\
\hline Error & 100 & 933.2 & 9.33 & & 59391067 & 593911 & & 11345038 & 113450 & & 96081 & 961 & \\
\hline
\end{tabular}

NB: the block source of variation refers to blocks within environments.

Table 4. Additive main effect and multiplicative interaction analysis of variance for plant height $(\mathrm{cm})$, panicle weight $(\mathrm{Kg})$, fresh biomass, and brix level (\%) of Dutch accessions

\begin{tabular}{|c|c|c|c|c|c|c|c|c|c|c|c|c|c|}
\hline \multirow{2}{*}{ Source } & \multirow{2}{*}{$\mathrm{DF}$} & \multicolumn{3}{|c|}{ Plant height $(\mathrm{cm})$} & \multicolumn{3}{|c|}{ Grain weight $(\mathrm{kg})$} & \multicolumn{3}{|c|}{ Biomass } & \multicolumn{3}{|c|}{ Brix level (\%) } \\
\hline & & SS & MS & Explained \% & $\mathrm{SS}$ & MS & Explained \% & SS & MS & Explained \% & SS & MS & Explained \% \\
\hline Total & 135 & 148708 & 1102 & & 31468297 & 233098 & & 236418462 & 1751248 & & 512.5 & 3.796 & \\
\hline Treatment & 67 & 107771 & $1609 * * *$ & 72.47 & 20180889 & $301207 * *$ & 64.13 & 157418762 & $2349534 * * *$ & 66.58 & 344.3 & $5.139 * *$ & 67.18 \\
\hline Genotype & 16 & 26396 & $1650^{*}$ & 17.75 & 7821686 & $488855 * * *$ & 24.85 & 36964149 & $2310259 * * *$ & 15.63 & 123.3 & $7.703 * *$ & 24.1 \\
\hline Environment & 3 & 33366 & $11122 * * *$ & 22.43 & 4094792 & $1364931 * *$ & 13.01 & 56283584 & $18761195^{* * *}$ & 23.8 & 59.1 & $19.695 * * *$ & 11.53 \\
\hline Blocks & 4 & 2119 & 530 & 1.42 & 3068738 & 767185 & 9.75 & 39580937 & 9895234 & 16.74 & 7.5 & 1.885 & 1.46 \\
\hline Interaction & 48 & 48009 & $1000^{*}$ & 32.28 & 8264412 & $172175^{* * *}$ & 26.26 & 64171029 & $1336896 * *$ & 27.14 & 162 & 3.374 & 31.61 \\
\hline IPCA 1 & 18 & 36621 & $2035^{* *}$ & 24.62 & 7096896 & $394272 * *$ & 22.55 & 44062714 & $2447929 * *$ & 18.64 & 118.5 & $6.586^{*}$ & 23.12 \\
\hline IPCA 2 & 16 & 9794 & 612 & 6.56 & 795743 & 49734 & 2.52 & 17845690 & $1115356^{*}$ & 7.54 & 36.6 & 2.288 & 7.14 \\
\hline Residual & 14 & 1594 & 114 & 1.07 & 371773 & 26555 & 26.12 & 2262624 & 161616 & 0.96 & 6.8 & 0.486 & 1.33 \\
\hline Error & 64 & 38818 & 607 & & 8218669 & 128417 & & 39418763 & 615918 & & 160.6 & 2.51 & \\
\hline
\end{tabular}

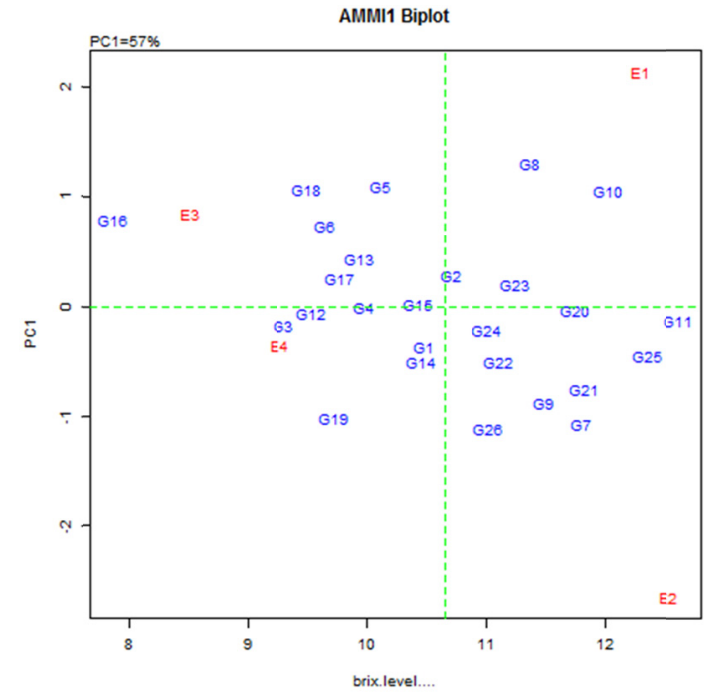

Figure 1a. (ICRISAT accessions)

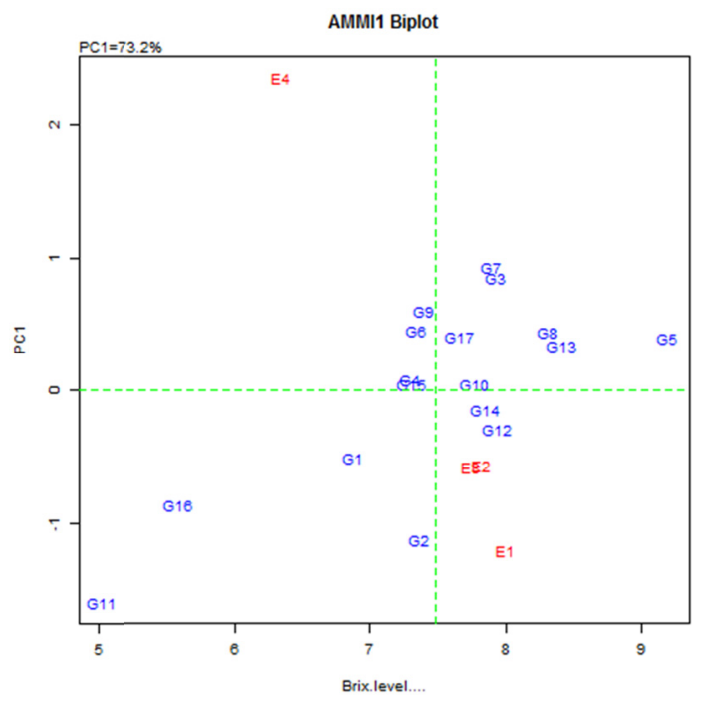

Figure 1b. (Dutch accessions)

Figure 1a, b. IPCA1 vs mean AMMI-1 biplot showing the relative mean performance of genotypes and environment for brix level 


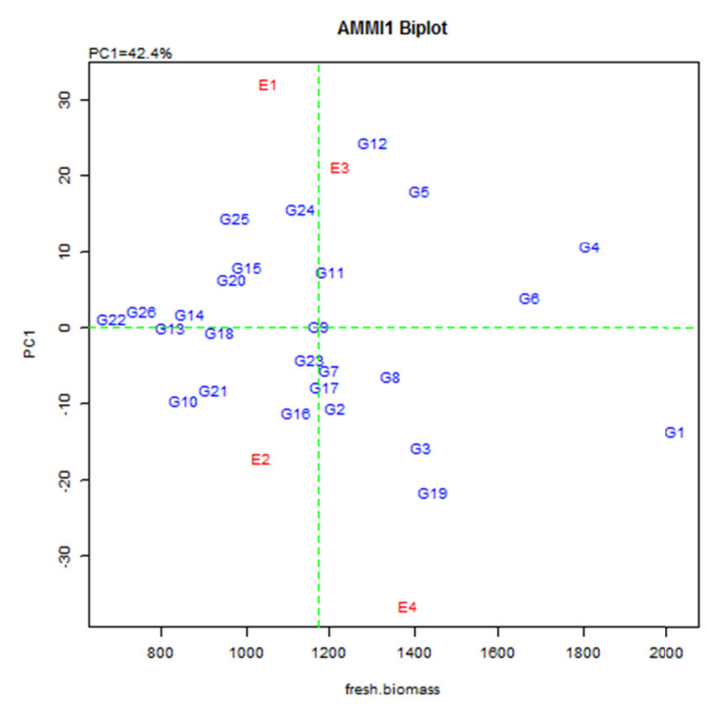

Figure 2a. (ICRISAT accessions)

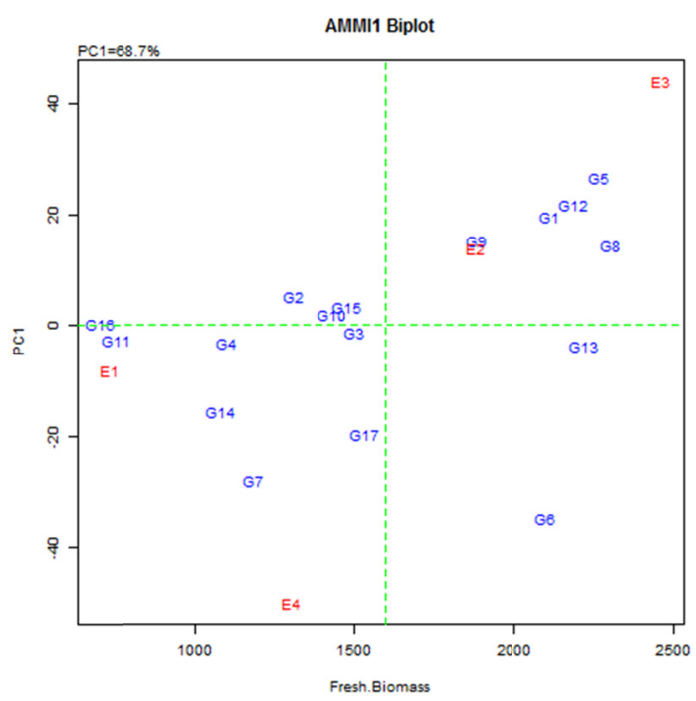

Figure 2b. (Dutch accessions)

Figure 2. IPCA1 versus mean AMMI-1 biplot showing the relative mean performance of genotypes and environment for fresh biomass among ICRISAT and DUTCH accessions

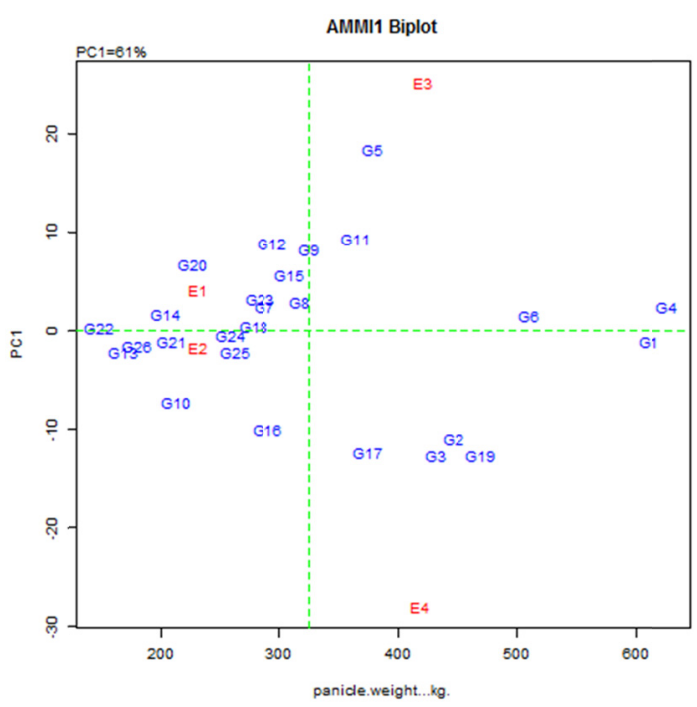

Figure 3a. (ICRISAT accessions)

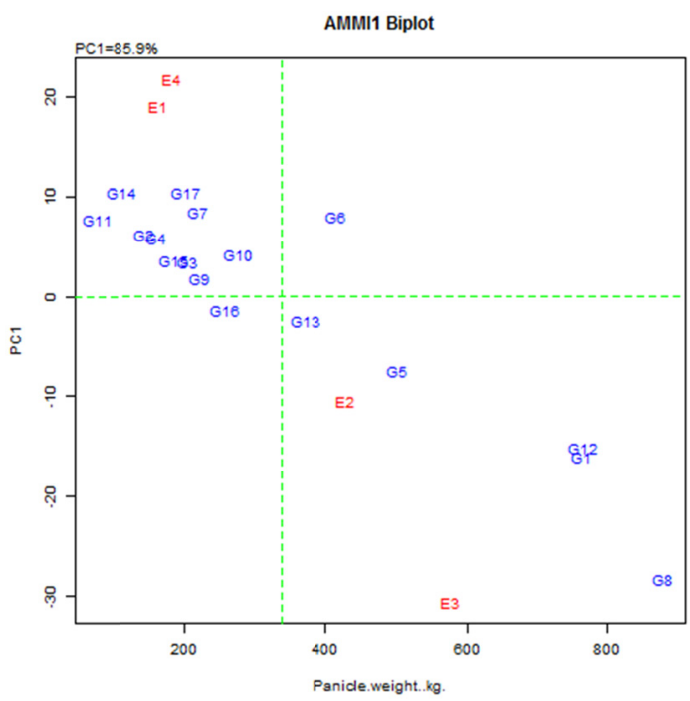

Figure 3b. (Dutch accessions)

Figure 3. IPCA1 vs mean AMMI-1 biplot showing the relative mean performance of genotypes and environment for panicle (grain) weight among ICRISAT accessions 


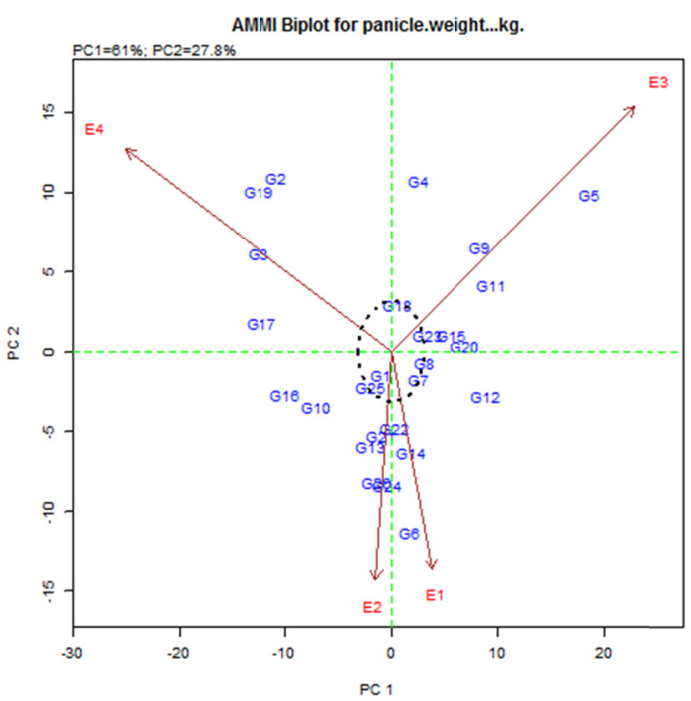

Figure 4a. (ICRISAT Accessions)

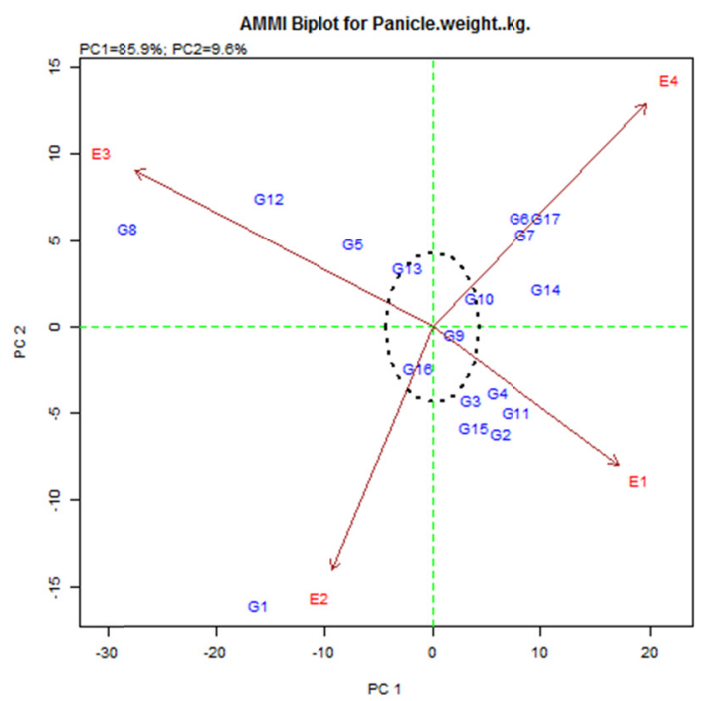

Figure 4b. (Dutch Accessions)

Figure 4. IPCA1 vs IPCA2 AMMI-2 biplot showing the interaction of the genotypes and environment for panicle (grain) weight among ICRISAT accessions

Key: The genotypes are numbered according to the serial number on the table.

The interaction between the genotype and environment for panicle (grain) weight is shown by IPCA1 vs IPCA2 AMMI-2 biplot analysis (Figure 4). The biplot explains $88.8 \%$ of variation due to interaction and indicate the stability of the genotypes and environment. The genotype G1 (F5.3SSM10-1/1-8), G7 (F5.3SSM10-14/1-1), G8 (F5.3SSm10-15/5-1), G18 (F5.3SSM10-8/1-5), G23 (F5.3SSM09-1-1/6-1 and G25 (F7.5SSM09-1-1/9-2) were indicated as the most stable genotypes for panicle weight as they exhibited very little interaction and were close to the origin of the biplot. Others are far from the origin of the biplot indicating low stability (Figure 4a) However, genotypes and environment near to each other on the biplot have positive interactions. For the Dutch accessions G9 (H3-R9-33/sn), G10 (H4-1-PD1-R47), G13 (H5-B1-R8-32-R2 and G16 (H8-R9-29/sn) were indicated as the most stable genotypes for panicle weight and were very close to the origin of the biplot (Figure $4 \mathrm{~b})$.

Figure 5 displays the IPCA1 vs IPCA2 AMMI-2 biplot showing the interaction of the genotypes and environment on degree of brix production of ICRISAT accessions. The biplot captured $80.9 \%$ of the total variation in brix level that is due to $\mathrm{G} \times \mathrm{E}$ interaction. The genotype $\mathrm{G} 11$ (F5.3SSM10-20/2-1), G15 (F5.3SSM10-24/2-1), G17 (F5.3SSM10-31/2-3) and G20 (F5.3SSM10-9/1-3) were indicated as the most stable genotypes for high brix level as they are closer to the origin of the biplot. There was no interaction between the environments. The biplot for the Dutch accessions captured $95.8 \%$ of the total variation in brix values due to $\mathrm{G} \times \mathrm{E}$ interaction. Two genotypes; G15 (H8-2-PD1-R47) and G4 (H18-PD3-R51) were indicated as the most stable for brix content as they were closer to the origin of biplot. 


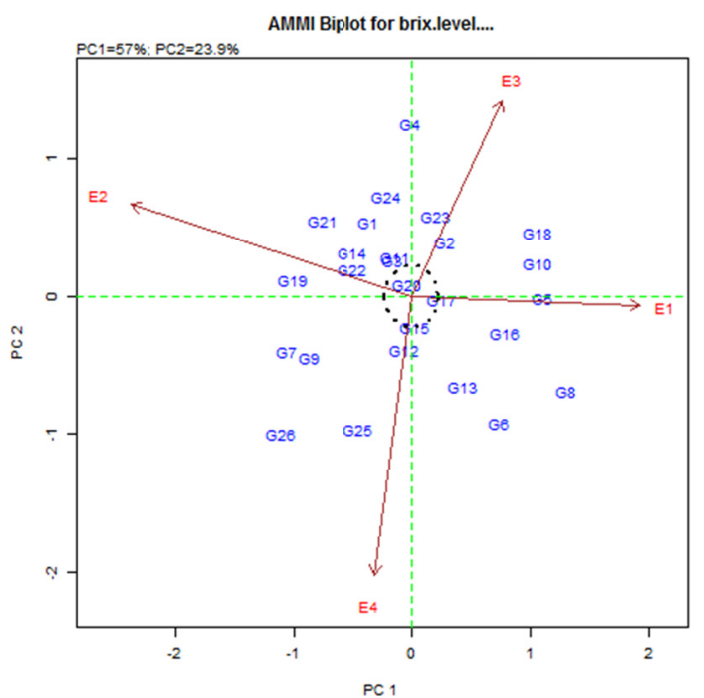

Figure 5a. (ICRISAT Accessions)

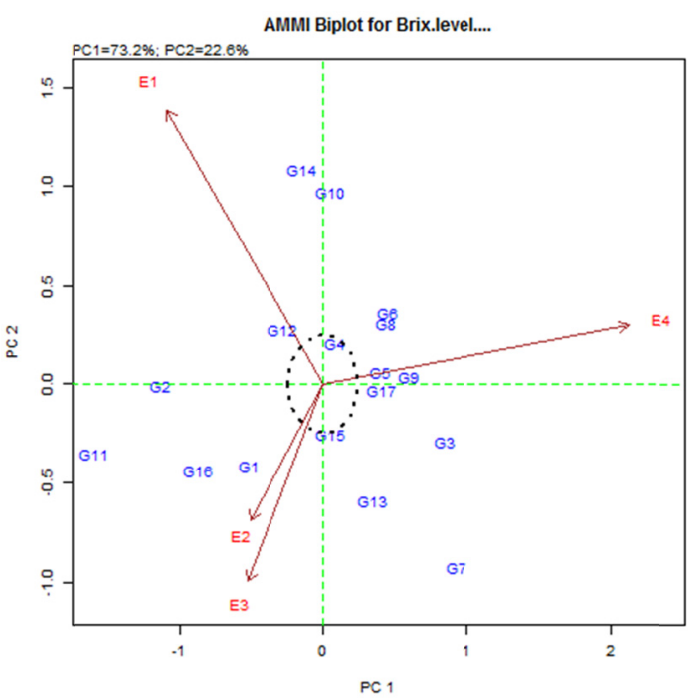

Figure 5b. (Dutch Accessions)

Figure 5. IPCA1 vs IPCA2 AMMI-2 biplot showing the interaction of the genotypes and environment for brix level among ICRISAT accessions

\section{Discussion}

The production potential of an environment is the ability of the environment to support superior performance from a series of genotypes. The significance shown by $\mathrm{G} \times \mathrm{E}$ implies that each of the genotypes reacted differently in various environments tested and thus local selection is required to obtain the best performance. The environmental effect were diverse, influencing each of the biofuel attributes directly which was in agreement with the result obtained by Reddy et al. (2014). This agrees with the report of Vijendra (2005) that when cultivars are compared in different environments, their performance relative to each other may not be the same. One genotype could perform in one environment and the second may supersede in others. Most of the yield attributes such as plant height, fresh biomass weight, grain yield and Brix levels are major traits in sweet sorghum required for biofuel production (Almodares et al., 2008; Murray et al., 2008).

Use of AMMI estimates which leads to ranking of genotypes facilitate selection. More precise yield estimate increases the probability of making successful selections (Crossa et al., 1990). In our analysis, the first IPCA1 (Interaction Principal Component Axis) was significant while the second principal component axis was not significant because of the limited number locations used for the test. However, AMMI model can be used only when one principal component axis is significant to explain the interaction between genotype and environment (Gebremedhin et al., 2014) for plant, fresh biomass weight, grain yield and Brix levels. From our field results two genotypes; F7.5 SSM09-1-1/7-2 and H8-R9-29/Sn were observed to be the tallest across the two environments. According to Abubakar and Bubuche (2013) GEI had a significant influence on sorghum height in Nigeria. Differences in plant height can result to changes in cane yield across environment. Therefore, genotypes adapted to specific location have indeed to be selected locally. The grain yield performance of F5.3 SSM10-1/6-6 and H1-PDI-R47 were consistently high in the two environments. The most stable in terms of grain yield among the sweet sorghum genotypes are F5.3 SSM10-15/5-1, and H3-2-PD1-R47.

The fresh biomass weight of the genotypes was location specific but genotype with highest fresh biomass weight across the location was F5.3 SSM10-1/6-6 and this genotype tends to be more stable. This genotype can be successfully selected for fresh biomass weight since biomass is one of the major biofuel contributors. According to Panhwar et al. (2003) the morphological characters such as stalk diameter, number of internode and stalk length influences the sugarcane yield. The biomass has positive relationship with yield and other related traits. Biomass yield and plant height have been found to be a major contributor to economic yield of sweet sorghum. Therefore, tall and robust sweet sorghum genotype should be selected to maximize cane yield. The Brix value was higher among the ICRISAT accessions than the Dutch accessions. Higher Brix values were obtained from genotypes planted in Denmark (mean $=12.4 \%$ ) than those planted in Nigeria (mean $=8.8 \%$ ). The same positive result was obtained in a previous study comparing sweet sorghum in Denmark and China (Mocoeur, 2015), which suggested that it is possible to reach high Brix content in short summers with long days. On the other hand, 
Dutch accessions perform better in Denmark than in Nigeria. This is contrary to the report of Fix and Seebaluck (2013) that higher solar radiation at initial growth and during ripening in sugarcane help to accumulate more sucrose. The ideal genotype according to Yan and Kang (2003) is a genotype with high mean performance and absolute stability. The genotype must have high yield across the location with minimum GEI (Ezatollah \& Mahsa, 2014). This report is confirmed by the results obtained on both fresh biomass weight and Brix value in which the genotype variances are greater than the variance due to interaction. The best performing genotypes with relative stability on each of the biofuel attributes (Plant height, fresh biomass weight, grain yield, brix levels) were about twenty-two genotypes among both ICRISAT and Dutch accessions. The performances were mostly location specific except few cases of sheared environments. From the available data collected the performance of the sweet sorghum is attributed to both genetic and environmental effects. Therefore genotypes adapted to specific locations or general stability across different environments has to be selected.

\section{Acknowledgements}

The scholarship by Niger Delta Development Commission (NDDC), Nigeria granted to Mr. Diana-Abasi Udoh is acknowledged and International Crops Research Institute for the Semi-Arid Tropics (ICRISAT), India for providing germplasm for the study.

\section{References}

Abubakar, L., \& Bubuche, T. (2013). Genotypes by environment interaction on biomass production in sorghum in northwestern Nigeria. African Journal of Agricultural Research, 8, 4460-4465. https://doi.org/10.5897/ AJAR2013. 6868

Almodares, A. R., Taheri, R., \& Adeli, S. (2008). Stalk yield and carbohydrate composition of sweet sorghum [Sorghum bicolor (L.) Moench] cultivars and lines at different growth stage. Journal of Malaysian Applied Biology, 37, 31-36.

Amosson, S., Grace, I., Bean, B., Rooney, W., \& Becker, J. (2011). Economic analysis for biofuel production in the Texas high plain. Retrieved from http://amanUo.tamu.edu/ files/2011/03/sweet sorghum

Belum, V. S., Reddy, A., Ashok, K., \& Ramesh, S. (2010). Sweet sorghum. ICRISAT, India.

Crossa, J., Gauch, H. C., \& Zobel, R. W. (1990). Additive main effect and multiplicative interaction analysis of two international maize cultivar trials. Crop Science, 30, 493-500. https://doi.org/10.2135/cropsci1990.00 11183 X003000030003x

Ezatollah, F., \& Mahsa, S. (2014). GGE Bi-plot analysis of genotype $\times$ environment interaction in Wheat-Agropyron Disomic Addition Lines. Agricultural Communication, 2(3), 1-7.

Fix, J., \& Seebaluck, V. (2013). Bioenergy for sustainable development and international competitiveness: The role of sugarcane in Africa, Routledge, New York. NY: USA.

Gebremedhin, W., Firew, M., \& Tesfye, B. (2014). Stability analysis of food barley genotypes in Northern Ethiopia. African Crop Science Journal, 22, 145-154.

Mocoeur, A., Zhang, Y.-M., Liu, Z.-Q., Shen, X., Zhang, L.-M., Rasmussen, S. K., \& Jing, H.-C. (2015). Stability and genetic control of morphological, biomass and biofuel traits under temperate maritime and continental conditions in sweet sorghum (Sorghum bicolour). Theoretical and Applied Genetics, 128, 1685-1701. https://doi.org/10.1007/s00122-015-2538-5

Murray, S. C., Sharma, A., Rooney, W. L., Klein, P. E., Mullet, J. E., Mitchell, S. E., \& Kresovich, S. (2008). Genetic Improvement of Sorghum as a Biofuel Feedstock. I. QTL for stem sugar and grain Nonstructural carbohydrate. Crop Science, 48, 2165-2179. https://doi.org/10.2135/cropsci2008.01.0016

Nzuve, F., Githiri, S., Mukunya, D. M., \& Gethic, J. (2013). Analysis of genotype x environment interaction for grain yield in maize hybrids. Journal of Agricultural Sciences, 5, 75-85.

Panhwar, R. N., Keerio, H. K., Khan, M. A., Rajpute, M. A., Unar, G. S., Mastoi, M. I., ... Keerio, A. R. (2003). Relationship between yield and yield contributing traits in sugarcane (Saccharum officinanun L.). Journal of Applied Sciences, 3, 97-99. https://doi.org/10.3923/jas.2003.97.99

Purchase, J. L. (1997). Parametric analysis to describe genotype x environment interaction and yield stability in winter wheat (Ph.D Thesis, Department of of Agronomy, Faculty of Agriculture, University of of Free State Bloemfontein, South Africa).

Rajvanshi, A., \& Nimbker, N. (2003). Sweet sorghum ideal for biofuel. Seed World, 14(8). 
Ramagosa, I., Borras-Gelonch, B., Slafer, G., \& Van Eeuwijk, F. (2013). Genotype by environment interaction and adaptation in sustainable food production (pp. 846-870). Springer, New York: N.Y., USA.

Reddy, P. S., Reddy, B. V. S., \& Rao, P. S. (2014). Genotype by sowing date interaction effects on sugar yield components in sweet sorghum (Sorghum bicolor L.) SABRAO Journal of Breeding and Genetic, 46, $24-255$.

Regassa, T. H., \& Wortmann, C. S. (2014). Sweet sorghum as a bioenergy crop: Literature review. Biomass and Bioenergy, 64, 348-355. https://doi.org/10.1016/j.biombioe.2014.03.052

Vijendra, L. D. das. (2005). Genetic and plant breeding (pp. 76-79). New Delhi: New Age International Limited Publishers.

Yan, W., \& Rajcan, J. (2002). Bi-plot analysis of test sites and traits relation in Ontario. Journal of Crop Science, 44, 11-20. https://doi.org/10.2135/cropsci2002.0011

Zobel, R. W., Wright, M. J., \& Guach, G. H. (1988). Statistical analysis of yield trial. Agronomy Journal, 80, 388-393. https://doi.org/10.2134/agronj1988.00021962008000030002x

\section{Copyrights}

Copyright for this article is retained by the author(s), with first publication rights granted to the journal.

This is an open-access article distributed under the terms and conditions of the Creative Commons Attribution license (http://creativecommons.org/licenses/by/4.0/). 